\title{
Erratum to: Drivers for energy efficiency and their effect on barriers: empirical evidence from Italian manufacturing enterprises
}

\author{
Enrico Cagno • Andrea Trianni • Giovanni Spallina • \\ Federico Marchesani
}

Published online: 13 December 2016

C) Springer Science+Business Media Dordrecht 2016

\section{Erratum to: Energy efficiency \\ DOI 10.1007/s12053-016-9488-x}

This paper was unfortunately published with error. The given name of one of the authors was incorrectly captured as "Vincenzo" when it should be "Giovanni." Further, the email address should be corrected to giovanni.spallina@mail.polimi.it. This was then corrected and is not anymore present in the published copies of the article.

The online version of the original article can be found under doi:10.1007/s12053-016-9488-x

\footnotetext{
E. Cagno · A. Trianni $(\bowtie) \cdot$ G. Spallina $\cdot$ F. Marchesani Department of Management, Economics and Industrial Engineering, Politecnico diMilano, Piazza Leonardo da Vinci 32, 20133 Milan, Italy

e-mail: andrea.trianni@polimi.it

E. Cagno

e-mail: enrico.cagno@polimi.it

G. Spallina

e-mail: giovanni.spallina@mail.polimi.it

F. Marchesani

e-mail: federico.marchesani@mail.polimi.it
} 